\title{
Disease Management Programme for Diabetes Mellitus in Nepal
}

\author{
Dulal RK, ${ }^{1}$ Karki S² \\ 'Patan Academy of Health Sciences, Lalitpur, Nepal, ${ }^{2}$ Nepal Army Hospital, Mahankal, Tundikhel, Kathmandu, Nepal.
}

\section{ABSTRACT}

Introduction: The prevalence of diabetes in elderly is being out-numbered and continuously rising. Individuals expect miracles from their health care providers as everything is curable in the eyes of the patient. Disease Management Programme for diabetes mellitus is sensible from the medical and economic point of view since it organizes care in multidisciplinary, multicomponent, proactive approach focusing on the whole course of a disease, using evidence-based standards of care that reduce health care costs and hospital stay. In Nepal, health care professionals today need to be aware that the patients are more and more aware about their disease and technology and their increased awareness demand innovative services.

Methods: Authenticated data used for the purpose of projection were drawn purely from urban or rural hospital-based. To estimate the prevalence of diabetes mellitus (DM), the data in pairs (i.e. prevalence and year) were fed into IDL - an inbuilt mathematical software program for best-fit regression. Literatures on DM prevalence and Disease Management Programme were examined.

Results: The overall projection for the DM prevalence in Nepal suggests that the prevalence of diagnosed DM will be 12.73\%, 15.11\% and 17.49\% in 2010, 2015 and 2020 respectively. Diabetes disease management programme appeared to be helpful in reduction of health care costs and hospital stay.

Conclusions: If the attributing factor for DM remains as it is today, many new cases of DM will be added each year. There is a need of effective disease management programme in the country. The increased level of awareness among the patients demands innovative services in future.

Key Words: diabetes, disease management programme, innovative services, projection

\section{INTRODUCTION}

The health of people has improved more in the past four generations than in the whole world history. ${ }^{1}$ In $2008,60 \%$ of all deaths in the world were from non-communicable diseases (NCD) including diabetes mellitus (DM). Of those deaths $80 \%$ occurred in low and middle-income countries. ${ }^{2}$
Apparently, the NCDs have become serious threat to the health of people in developing countries which ranked as the third most likely risk to come true and the fourth most severe in its impact in $2009 .^{3}$

Roughly one in ten Nepalese are found to have DM where women are slightly more affected than men $(59.1 \%$ vs. $56.8 \%){ }^{4}$ Studies indicated that overall DM prevalence in rural and urban

Correspondence:

Dr. Ram Krishna Dulal

Patan Academy of Health Sciences

GPO Box 26500, Sundhara, Kathmandu, Nepal. Email: dulal@uni-bremen.de

Phone: 9851025545 
population has increased to $25.9 \%$ in $2009^{5}$ which was $19.07 \%$ in urban population in aged 40 years and over. ${ }^{6}$ Earlier, DM prevalence was reported $14.6 \%$ in urban population in aged 20 years and above, ${ }^{7}$ that was just $2.4 \%$ in the rural and $12.3 \%$ in the urban population in 2000 . The same study reported $3.1 \%$ in the rural and $15.5 \%$ urban population.

Chronic NCDs are persistent or recurring; they are often incurable and progress with increasing severity. Many of them can be asymptomatic for a long period of time. Death due to NCDs in Nepal is $42.1 \%$ compared to $48.9 \%$ for South Asia. 9,10 Effective managed care to tackle DM is sensible from the medical and economic point of view where 'Disease Management Programme' (DMP) organizes health care in multidisciplinary, multicomponent, proactive approach focusing on the whole course of a disease, using evidence-based standards of care that is associated with a significant reduction in health care costs and hospital stay. ${ }^{11,12}$

Now, the Nepalese health care managers and professionals have to be aware that the patients are more and more aware about their disease including available technology. With the advances and innovative medical technology, everything is "curable" in their eyes. Individuals expect "miracles" from their health care providers ${ }^{13}$ and could demand innovative services.

\section{METHODS}

Authenticated data used for the purpose of projection in this study were from the inference drawn purely from urban or rural hospital-based records as a precise national surveillance data was unavailable. Literatures on DM prevalence and Disease Management Programme were analyzed. DMP is being proven as an effective and also money saver to a national economy.
The authors gathered information on DM studies carried out in Nepal and their results that were published elsewhere for the purpose of prevalence forecasting. The data included for the purpose of projection were as follows:

1) A rural community cross sectional survey comprising 604 subjects (2003). ${ }^{7}$

2) A urban community cross sectional survey comprising 1237 subjects (2003). ${ }^{7}$

3) A rural community cross sectional survey comprising 211 subjects (2000). ${ }^{8}$

4) A urban community cross sectional survey comprising 114 subjects (2000). ${ }^{8}$

5) Cohort data from a university teaching hospital comprising 225 indoor patient published in $1995 .^{15}$

6) Cohort data from a central hospital (public hospital) comprising 3,768 admitted patients during April 1990 to March1991; 3,545 admitted patients during April 1991 to March 1992; 3,562 admitted patients during April 1992 to March 1993; 3,620 admitted patients during April 1993 to March 1994 (1995). ${ }^{14}$

7) A university status teaching hospital-based data (Laboratory) comprising 920 subjects (2002). 16

8) A university status teaching hospital-based data (Ambulatory) comprising 1840 subjects (2000). ${ }^{17}$

Prevalence data documented in the urban community and community hospital-based studies are involved in this inference. In order to estimate the prevalence of DM, the authors fed the data in pairs (i.e. prevalence and year) into IDL - an inbuilt mathematical software program for best-fit regression. Then based on the data, prevalence estimation was done for the year 2010, 2015 and 2020.

Table 1. Diabetes studies in urban and rural

\begin{tabular}{|c|c|c|c|c|c|c|c|c|c|}
\hline $\begin{array}{l}\text { Authors } \\
\text { (number) }\end{array}$ & $\begin{array}{l}\text { Study } \\
\text { period }\end{array}$ & $\begin{array}{l}\text { Study } \\
\text { population } \\
\text { (number) }\end{array}$ & $\begin{array}{l}\text { Diabetes } \\
\text { prevalence }\end{array}$ & $\begin{array}{l}\text { DM in } \\
\text { urban } \\
\text { population }\end{array}$ & $\begin{array}{l}\text { DM in } \\
\text { rural } \\
\text { population }\end{array}$ & $\begin{array}{l}\text { IGT } \\
\text { preva- } \\
\text { lence }\end{array}$ & $\begin{array}{l}\text { IGT in } \\
\text { urban } \\
\text { population }\end{array}$ & $\begin{array}{l}\text { IGT in } \\
\text { rural } \\
\text { population }\end{array}$ & $\begin{array}{l}\text { Remarks } \\
\mathrm{n}\end{array}$ \\
\hline \multicolumn{10}{|l|}{ Chhetri MR, Chapma } \\
\hline RS $(2009)^{5}$ & NA & 1633 & 25.9 & & & - & & & Urban + Rural \\
\hline $\begin{array}{l}\text { Shrestha UK } \\
(2002)^{6}\end{array}$ & $2001 / 2002$ & 1012 & 19.04 & 19.07 & - & - & $\begin{array}{l}7 \text { ( } \geq 40 \\
\text { years) }\end{array}$ & - & $\begin{array}{l}\text { Urban community } \\
\text { survey }\end{array}$ \\
\hline $\begin{array}{l}\text { Singh DL, Bhattarai } \\
\text { MD (2003) }\end{array}$ & $\begin{array}{l}\text { Jan.1999 } \\
\text { /Dec.2001 }\end{array}$ & 604 & 2.5 & - & 2.5 & - & - & 1.3 & $\begin{array}{l}\text { Rural community } \\
\text { survey }\end{array}$ \\
\hline $\begin{array}{l}\text { Singh DL, Bhattarai } \\
\text { MD (2003) }\end{array}$ & $\begin{array}{l}\text { Jan.1999 } \\
\text { /Dec.2001 }\end{array}$ & 1237 & 14.6 & 14.6 & - & - & 10.7 & - & $\begin{array}{l}\text { Urban community } \\
\text { survey }\end{array}$ \\
\hline $\begin{array}{l}\text { Singh DL } \\
\text { et al. }(1995)^{14}\end{array}$ & $\begin{array}{l}\text { April } 1990 \\
\text { /March'91 }\end{array}$ & 3768 & 2.6 & - & - & - & - & - & $\begin{array}{l}\text { Hospital-based } \\
\text { data (In- patient) }\end{array}$ \\
\hline $\begin{array}{l}\text { Singh DL } \\
\text { et al. }(1995)^{14}\end{array}$ & $\begin{array}{l}\text { April } 1991 \\
\text { /March'92 }\end{array}$ & 3545 & 2.9 & - & - & - & - & - & $\begin{array}{l}\text { Hospital-based } \\
\text { data (In- patient) }\end{array}$ \\
\hline $\begin{array}{l}\text { Singh DL } \\
\text { et al. }(1995)^{14}\end{array}$ & $\begin{array}{l}\text { April } 1992 \\
\text { /March'93 }\end{array}$ & 3562 & 4.3 & - & - & - & - & - & $\begin{array}{l}\text { Hospital-based data } \\
\text { (In- patient) }\end{array}$ \\
\hline $\begin{array}{l}\text { Singh DL } \\
\text { et al. }(1995)^{14}\end{array}$ & $\begin{array}{l}\text { April } 1993 \\
\text { /March'94 }\end{array}$ & 3620 & 5.6 & - & - & - & - & - & $\begin{array}{l}\text { Hospital-based data } \\
\text { (In- patient) }\end{array}$ \\
\hline
\end{tabular}


Dulal et al. Disease Management Programme for Diabetes Mellitus in Nepal

\begin{tabular}{|c|c|c|c|c|c|c|c|c|c|}
\hline $\begin{array}{l}\text { Bhattarai MD } \\
(2000)^{8}\end{array}$ & 2000 & 211 & 2.4 & - & 2.4 & - & - & $\begin{array}{l}1.4 \\
\text { and } 1.9\end{array}$ & $\begin{array}{l}\text { Rural community } \\
\text { survey }\end{array}$ \\
\hline $\begin{array}{l}\text { Bhattarai MD } \\
(2000)^{8}\end{array}$ & 2000 & 114 & 12.3 & - & - & - & 5.3 & - & $\begin{array}{l}\text { Urban community } \\
\text { survey }\end{array}$ \\
\hline $\begin{array}{l}\text { Acharya GP } \\
(1995)^{15}\end{array}$ & 1994 & 225 & 9.5 & - & - & - & - & - & $\begin{array}{l}\text { Hospital-based data } \\
\text { (In- patient) }\end{array}$ \\
\hline $\begin{array}{l}\text { Baral N } \\
\text { et al. }(2000)^{16}\end{array}$ & 2000 & 920 & 5.29 & - & - & 18 & - & - & $\begin{array}{l}\text { Hospital-based data } \\
\text { (Laboratory) }\end{array}$ \\
\hline $\begin{array}{l}\text { Karki P et al. } \\
(2000)^{17}\end{array}$ & 2000 & 1840 & 6.3 & - & - & - & - & - & $\begin{array}{l}\text { Hospital-based data } \\
\text { (Ambulatory) }\end{array}$ \\
\hline
\end{tabular}

\section{RESULTS}

DM prevalence is increasing in Nepal, but it is somewhat in an unpredictable scale [Figure 1 (a) and Table 1]. The overall projection for the DM prevalence suggests that the prevalence of diagnosed DM will be $12.73 \%$, $15.11 \%$ and $17.49 \%$ in 2010, 2015 and 2020, respectively [Figure1 (b)]. The result is based on the data fed from the hospital-based studies only (Bir Hospital, BP Koirala Institute of Health Science $(\mathrm{BPKIHS})^{17}$ and Tribhuvan University Teaching Hospital (TUTH).
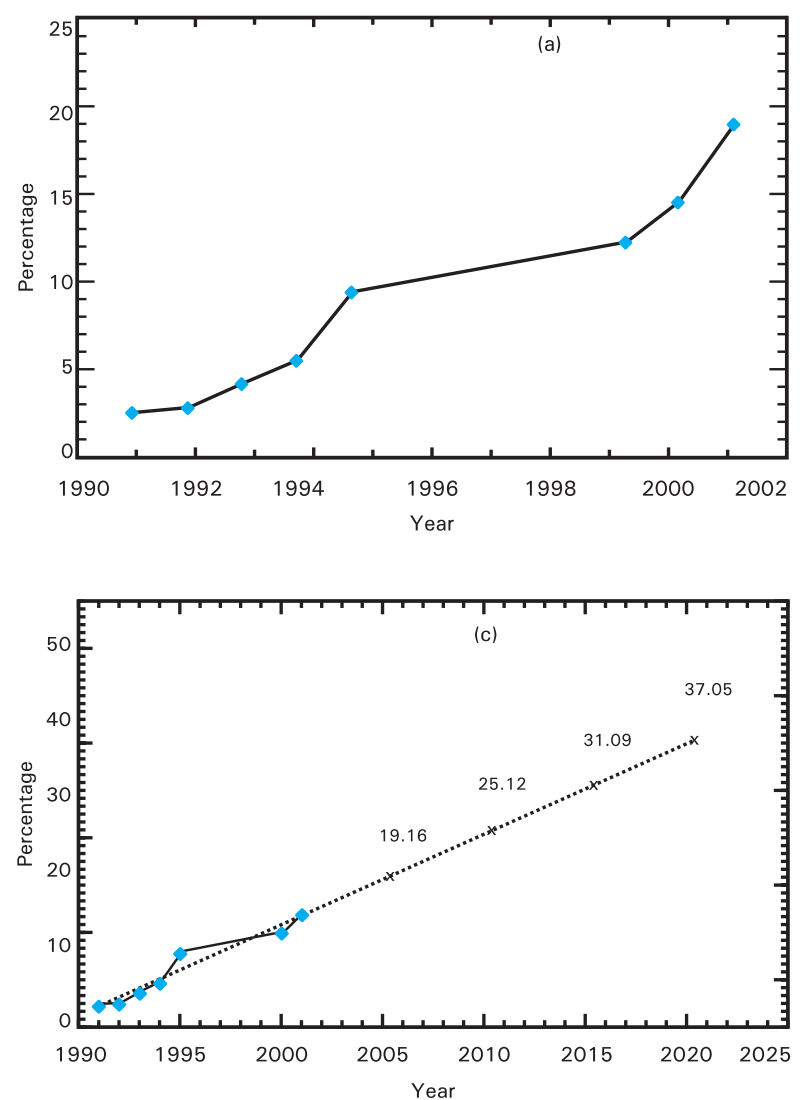

The overall projection using paired data from urban community-based studies by Bhattarai (2000) and Singh and Bhattatai (2003) suggests that the prevalence of diagnosed DM will be $25.12 \%, 31.09 \%$ and $37.05 \%$ in 2010, 2015 and 2020, respectively, [Figure 1(c)].

DM prevalence projected to be sharply increased when data was taken from the urban community-based study. ${ }^{6}$ It suggests that the prevalence of diagnosed DM will be $27.78 \%, 34.54 \%$ and $41.29 \%$ in 2010,2015 and 2020, respectively [(Figure 1 (d)].
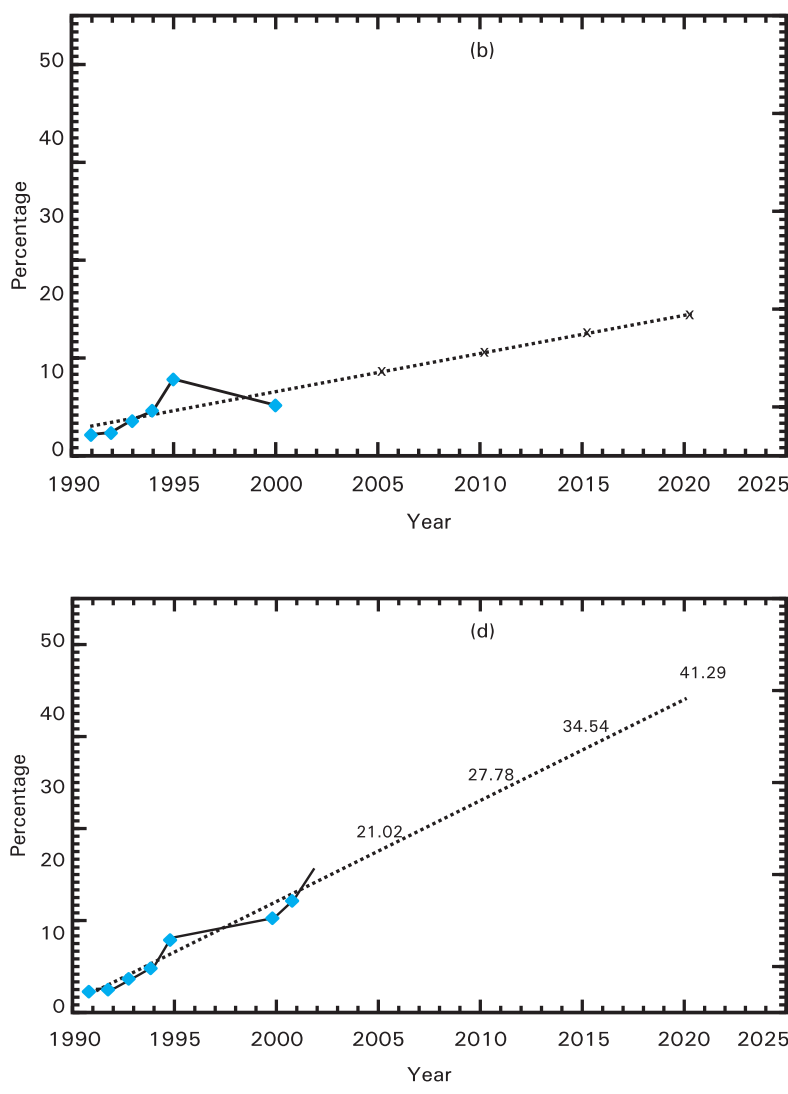

Figure 1. Diabetes Prevalence Projection 


\section{DISCUSSION}

Nepal has the highest prevalence of pre-diabetes (impaired glucose tolerance) and diabetes mellitus type 2 among four countries (Bangladesh, India, Nepal and Pakistan) in South East Asia (Table 2). ${ }^{18}$ DM type 2 has been increasing which was once thought to be a problem exclusively of developed countries and the wealthy. ${ }^{5}$ This illustration has now been proven incorrect as poor are also affected by DM in developed countries and rich in the developing countries. Though precise national prevalence figure is unavailable, a couple of early studies indicated that the prevalence has increased i.e. $25.9 \%$ in aged 60 and over in urban and rural combined result, $19.04 \%$ in aged 40 and over and $14.6 \%$ in aged 20 years and over urban adults. ${ }^{5-7}$ Studies conducted in aged 60 years and over in Kathmandu Metropolitan City-35, Chapagaon VDC of Lalitpur and Jhoukhel VDC of Bhaktapur) illustrated that overall undiagnosed DM was more than double than the diagnosed in the previous study. ${ }^{5}$ This result substantiates the previous study which reported $54.4 \%$ (53.8\% of men and $55.1 \%$ of women) undiagnosed diabetes. ${ }^{7}$

In 1995, a university teaching hospital-based study situated in central development region reported DM in $9.55 \%{ }^{15}$ which is much higher compared to $2.6 \%$ at the central government hospital in Kathmandu in April 1990 to March $1991 .{ }^{14}$ The same authors reported DM in 5.6\% of its inpatients admitted during April 1993 to March1994 in the same setting.

The teaching hospital of BP Koirala Institute of Health Science (BPKIHS) in eastern part of Nepal reported DM in $5.29 \%{ }^{16}$ in OGTT test and in another study conducted in ambulatory clinic of the same hospital reported DM in $6.3 \% .{ }^{17}$ Due to variability in the study population, place and nature of the institutions, the data is weak. Ascertainment was still much better as population studies were the admitted patients at Bir Hospital that represents whole population of the country as being a general community hospital.

Tribhuvan University Teaching Hospital and BP Koirala Institute of Health Sciences being teaching hospitals do cover people from all walks of life. So, this data roughly represents countries scenario. The data is used as a base line data since no other authentic data was available.

BPKIHS in eastern hilly region covers the rural as well urban population. It is situated almost in the centre neighbouring with prosperous districts including Sunsari and Morang. It might have influenced the lifestyle and food behaviour that might have contributed to increased diabetes prevalence. Generally, approximately $50 \%$ of the cases of diabetes remain undiagnosed, even in countries where there is an advanced health-care system. The health-care situation in Nepal is obviously different from those countries and it is reported that approximately $50 \%$ of the cases are undiagnosed. A study conducted in various urban clusters of Kathmandu shows that $54.4 \%$ of the total number of diabetics was reported to have previously been undiagnosed..$^{19}$

The scenario clearly indicates that the DM prevalence has been increasing in Nepal. Then again, Nepal is transforming to modernism where competition in consumerism has already become apparent. The individuals who consume rich-nutrients and fatty food and at the same time exert progressively less physical energy in their work are prone to put on weight, which leads to obesity; and obesity is one of the leading causes for developing DM. The DMP could be one of the vital models to tackle future DM burden in Nepal since it comprises integrated approach of evidence-based care that includes counselling.

If the current trend continues the number of persons with diabetes will be more than double in the next 25 years. A study projected that the cases of DM type 2 will be 299.1 million worldwide by the year 2025 and 79.5 million cases would be in South East Asia alone. ${ }^{20}$

Table 2. Diabetes type 2 Prevalence in SAARC countries

\begin{tabular}{llll}
\hline Country & \multicolumn{2}{l}{ Prevalence of type 2 diabetes } & Male/Female \\
\hline & Urban & Rural & Ratio \\
Bangladesh & $7.9 \%$ & $3.8 \%$ & 1.15 \\
India & $12.1 \%$ & $2.9 \%$ & 1.05 \\
Nepal & $14.1 \%$ & $2.9 \%$ & 1.31 \\
Pakistan & $10.8 \%$ & $6.5 \%$ & 1.32 \\
\hline
\end{tabular}

In SAARC region DM prevalence in urban areas is reported to be alarming. In 2002, White and Rafique summarized DM data in the South Asian countries and reported the prevalence higher than the WHO value for developing countries $(3.5 \%)$. Among the four countries in SAARC region, DM prevalence in Nepal is the highest (Table 2). ${ }^{21}$

\section{Major Consequences of Diabetes}

Table 3. The statistics of diabetes mellitus complications in Germany

\begin{tabular}{llll}
\hline Complications & Cases per year & Bremen & $\begin{array}{l}\text { Risk increased by } \\
\text { diabetic mellitus }\end{array}$ \\
\hline Heart infarction & $90,000(35,000$ death $)$ & $720(280)$ & $3-6$ \\
Heart Failure & $120,000(30,000$ death $)$ & $960(240)$ & $2-3$ \\
Amputation & 28,000 & 224 & 45 \\
Blindness & 7,000 & 56 & $10-25$ \\
Kidney failure & 9,000 & 72 & $15-20$ \\
\hline
\end{tabular}


High blood sugar is the hallmark of DM that increases the risk of complications. Failure to control elevated blood sugar or inadequate treatment of DM could cause number of complications. A report on DM and its risk factors indicated that risk of heart infarction increased by 3-6 times. Similarly, it increases risk of heart failure by 2-3 times, risk of amputation 45 times, blindness 10-25 times and kidney failure 15-20 times (Table.3). ${ }^{22}$

Table 4. Diabetic complications.

\begin{tabular}{llll}
\hline $\begin{array}{l}\text { Duration of } \\
\text { DM (Years) }\end{array}$ & $\begin{array}{l}\text { Neuropathy } \\
(\%)\end{array}$ & $\begin{array}{l}\text { Retinopathy } \\
(\%)\end{array}$ & $\begin{array}{l}\text { Nephropathy } \\
(\%)\end{array}$ \\
\hline 0 & 8 & 5 & 0 \\
5 & 15 & 16 & 2 \\
10 & 26 & 26 & 5 \\
15 & 31 & 40 & 8 \\
20 & 40 & 48 & 10 \\
25 & 49 & 50 & 10
\end{tabular}

$\varnothing \mathrm{Nepal}$ data on the table by White and Rafique.

The patients living longer with DM have higher risk of developing complications like neuropathy, retinopathy and nephropathy e.g. if a person is living with DM for 25 years, a probability of getting neuropathy, retinopathy and nephropathy will be $49 \%, 50 \%$ and $10 \%$ respectively.

But, if a person is living with DM for fewer years, a probability of getting neuropathy, retinopathy and nephropathy will lesser e.g. person living with DM for 5 years will have neuropathy, retinopathy and nephropathy $15 \%, 16 \%$ and $2 \%$ respectively. $^{23}$

Disease Management Programme: Money Saver and Outcome Improver

The concept of disease management programme (DMP) has been introduced to implement evidence-based clinical practice and guidelines, care protocols, to improve coordination among healthcare providers and assure continuity and comprehensiveness of care. DMPs organize health care in multidisciplinary, multicomponent, proactive approach focusing on the whole course of a disease, using evidencebased standards of care. They are characterized by three main features: a knowledge base, a delivery system with coordinated care components, and a continuous improvement process though the above mentioned components are diverse and heterogeneity in nature.

In this context, the management of any disease is realized through coordinated and integrated care, focused on the entire pre-clinical and clinical development of the disease: early diagnosis, treatment and rehabilitation, as well as towards health promotion and disease prevention through reduction of risk factors levels in the living environment, introduction of healthy behaviours and lifestyle, and increasing the quality and effectiveness of medical services. The DMP is a broad term, comprising of various methods, forms of interventions, organizational approaches and technologies. ${ }^{11}$ Disease management programme help to reduce the costly rehospitalisation days. ${ }^{12}$ For an example a retrospective study comprising 6,799 individuals continuously enrolled for diabetes were divided into two groups to examine whether DMP saves money and improves the outcomes. A total of 3,118 (45.9\%) patients were enrolled in a disease management program (program), and 3,681 (54.1\%) were not enrolled (non-program). Both groups had similar male-to-female ratios, and the program patients were 1.4 years younger than the nonprogram patients.

Per member per month paid claims averaged $\$ 394.62$ for program patients compared with $\$ 502.48$ for nonprogram patients $(P=0.05)$. This difference was accompanied by lower inpatient health care use in program patients than in non-program patients. Program patients experienced fewer emergency room visits than nonprogram patients but had a higher number of primary care visits (8.36 vs. 7.78, $\mathrm{P}=0.05$ for both measures). Except for emergency room visits, these differences remained significant after controlling for age, sex, HMO enrollment duration, presence of a pharmacy benefit, and insurance type. Program patients also achieved higher health employer data and information set scores for $\mathrm{HbA} 1 \mathrm{c}$ testing as well as for lipid, eye, and kidney screenings. It proves that DMP could be an important tool (program) to improve diabetes health care as it is an effective and economic one.

Based on the global scenario and also South Asian and Nepalese scenario of diabetes mellitus, the authors are convinced that diabetes will be increasing in Nepal. The current approach of delivering diabetes care through integrated manner in general OPDs through medical officers 10 (juniors) be replaced by DMP where different specialities (diabetologists, nephrologists, cardiologists, ophthalmologists, nurses) service would be accessible.

A study evaluating disease management programme for diabetes in aged 61 years or older in Germany who had suffered from diabetes or received treatment for more than 5 years. The research finding was that the proportion consulting a specially trained diabetology physician did double to $31 \%$. The assessment of the quality of care improved markedly; $19 \%$ of the diabetes patients reported improvement in their status. ${ }^{24}$

\section{Risky Future}

The 'Population Census 2001' shows that $14.2 \%$ of the total population of 23.2 million lived in the 58 urban areas of Nepal. It is the highest urbanization in the South East Asian Region. This figure should have gone up by now. It is estimated that the total number of urban residents will reach $50 \%$ or more of the entire population within 10 years and will be double the amount in 18 years. ${ }^{25}$ The urban population in developing country, particularly, the economically well-off are more vulnerable to develop diabetes compared to rural ones. DM prevalence among the urban subjects is many times higher than the rural ones (urban $8.2 \%$ vs. rural $2.4 \%$ ) in India. The study described that diabetes was found to be more than two fold higher in an urbanizing peripheral (e.g. suburban) town in India (5.9\%) than in rural areas $(2.4 \%)$ which is between the rural and urban rates $(11.6 \%)$. The urban diabetes prevalence figure $(11.6 \%)$ that they described was referring to one another study by the 
same author. ${ }^{26}$ Thus, with an increasing urbanization lifestyle of people will gradually be influenced.

The evidence shows that DMP works well, it costs less; and we know that we the Nepalese particularly those living in urban are at higher risk. Thus, Nepal should consider establishing a Disease Management programme to provide evidence based integrated care and promote a better quality of life.

Initially, DMP that is dedicated to Diabetes Mellitus (DM) management should provide all the essential care components for DM. The care components include routine blood tests (HbA1C, lipid profile), blood pressure checks and annual assessment of the eye, kidney and feet. DMP should organize and direct health care services to needy people who are suffering from the disease. DMP is to be established and promoted as a way to increase quality care with low cost for national health system and individuals. The services must include health manpower (diabetologists, nephrologists, cardiologists, ophthalmologists, nurses) and well as other preventive and promotive services and also hospital beds with medicines and materials.

\section{CONCLUSIONS}

Previous studies and our projected result indicate that the prevalence of diabetes will be increasing. As a result of DM, new cases of diabetes complication could also be increasing. In order to tackle DM and DM related health care issues, a Disease Management Programme could be helpful to deliver quality and cost effective service.

\section{REFERENCES}

1. WHO. Why invest in health research? Historical experience and the promise of science in Investing in Health Research and Development. Geneva: World Health Organization; 1996. p. 1.

2. WHO. 2008-2013 Action Plan for the Global Strategy for the Prevention and Control of Noncommunicable Diseases. WHO Document Production Services. Geneva, Switzerland: World Health Organization; 2008.

3. Non communicable Diseases, Poverty and the Development Agenda. In: ECOSOC/UNESCWA/WHO. Addressing non communicable diseases and injuries: major challenges to sustainable development in the 21st century. Proceedings of the Western Asia Ministerial Meeting; 2009 May 5; Doha, Qatar.

4. MOHP. Nepal National Policy, Strategy and Plan of Action for Prevention and Control of Non-Communicable Diseases. Kathmandu: Government of Nepal Ministry of Health and Population Nepal; 2009 (Unpublished Draft Report).

5. Chhetri MR, Chapma RS. Prevalence and determinants of diabetes among the elderly population in the Kathmandu Valley of Nepal. Nepal Med Coll J. 2009;11(1):34-8.

6. Shrestha UL, Singh DL and Bhattarai MD. The prevalence of hypertension and diabetes defined by fasting and 2-h plasma glucose criteria in urban Nepal. Diabet Med. 2006 Oct;23(10):1130-5

7. Singh DL and Bhattarai MD. High prevalence of diabetes and impaired fasting glycaemia in urban Nepal (letter). Diabet Med. 2003 Feb;20(2):170-1.

8. Bhattarai MD. Diabetes in Nepal, diabetes in the Middle East, Eastern Mediterranean \& South East Asia (DIMEMSEA). Proceedings of the Second Conference; 2000 March 2-4; Dhaka, Bangladesh; 2000. p. 22-3.

9. Suvedi BK. Of what diseases are Nepalese dying? Kathmandu Univ Med J (KUMJ). 2007 Jan-Mar;5(1):121-3.

10. Gazewood JD. Introduction to chronic illness. [Online]. 2008 [Cited 2008 September 25]. Available from: http://hsc.virginia.edu/meded/pom/handouts/pdf/Introduction \%20to\%20Chronic\%20Illness_G azewood.PDF

11. Dyakova M, Karaslavova ES, Dobriana. Disease Management Programs. The case of CVD Management in Bilgaria. In: A Handbook for Teachers, Researchers and Health Professionals. [Online]. 2002 [Cited 2002 Sep 25]. Available from: http://biecoll.ub.uni-bielefeld.de/-volltexte/2009/2128/pdf/Dokument3_8.pdf

12. Daly BJ, Douglas SL, Kelley CG, O'toole E, Montenegro H. Trial of a Disease Management Program to Reduce Hospital Readmissions of the Chronically Critically Ill. Chest. 2005 Aug;128(2):507-17.

13. Lombardi DN. Handbook for the new health care manager, Practical strategies for the real world. $2^{\text {nd }}$ ed. San Francisco: Jossey-Bass Inc; 2001. p.7.
14. Singh et al. Demographic profile of diabetic patients admitted in the medical wards of Bir Hospital, Nepal, 1990 to 1994. International Diabetes Digest. 1995;6(4)87-8.

15. Acharya GP. Diabetes mellitus at Tribhuvan University Teaching Hospital. In: International Symposium on Diabetes Mellitus; 1995 Mar 23-24; Kathmandu, Nepal; 1995. p. 7.

16. Baral N, Koner BC, Karki P, Ramaprasad C, Lamsal M, Koirala S. Evaluation of new diagnostic criteria for diabetes on the prevalence of abnormal glucose tolerance in heterogeneous Nepali population - The implications of measuring glycated haemoglobin. Singapore Med J. 2000 Jun;41(6):264-7.

17. Karki P, Baral N, Lamsal M, Rijal S, Koner BC, Dhungel S, et al. Prevalence of non-insulin dependent diabetes mellitus in urban areas of eastern Nepal: a hospital based study. Southeast Asian J Trop Med Public Health. 2000 Mar;31(1):163-6.

18. White F, Rafique G. Diabetes prevalence and projections in South Asia Lancet. 2002 Sep 7;360(9335):804-5.

19. Dulal RK. A perspective health care model for Nepal to reduce burden of Diabetes Mellitus through policy appraisal of Germany and Great Britain [thesis]. Bremen, Germany: University of Bremen; 2004.

20. King H, Aubert RE, Herman WH. Global burden of diabetes, 1995-2025: prevalence, numerical estimates, and projections. Diabetes Care. 1998 Sep;21(9):1414-31.

21. White F and Rafique G. Diabetes prevalence and projections in South Asia. Lancet. 2002;360(9335):804-5.

22. Pfuhl J and Stroth H. Vorsorgungsstrukturen für Diabetiker in Bremen. Bremen: 2000 Mar. p. 2.

23. Williams G and Pickup JC. Diagnosis and classification of diabetes mellitus. In: Handbook of Diabetes. Oxford: Blackwell Scientific Publications; 2002.

24. Elkeles T, Heinze S and Eifel R. Health care by a DMP for diabetes mellitus type 2-results of a survey of participating insurance customers of a health insurance company in Germany. J Public Health. 2007;15:473-80.

25. Koirala GP. Demographic dynamics, changing consumption pattern, poverty, agriculture and rural development, role of farmers in sustainable development, sectoral reports on Sustainable Development Agenda for Nepal (SDAN). [Online]. 2002 [Cited 2009 Jun 25]. Available from: http://www.scdp.org.np/sdan/SDANrpt1.pdf.

26. Ramachandran A, Chamukuttan S, Viswanathan V. Explosion of type 2 diabetes in the Indian subcontinent. International Diabetes Monitor. 2003;15(5):1-6. 